\title{
On the Sintering of Single Crystal Rutile
}

\author{
H. M. O'BRYAN, JR.* AND G. PARRAVANO \\ Department of Chemical and Metallurgical Engineering, University of Michigan, Ann Arbor, Mich. (U.S.A.)
}

(Received May 23, 1966: revised July 14, 1966)

\begin{abstract}
$S U M M A R Y$
The sintering of single crystal rutile spheres has been studied in air and in reducing atmosphere in the temperature range 900 to $1350^{\circ} \mathrm{C}$. The rate of sintering is characterized by two stages: a slow initial one, followed by a more rapid period. Simultaneously with the change in sintering rate, flat surfaces develop on the rutile spheres. It is suggested that this phenom-

enon is responsible for the change in sintering rate.

From qualitative and quantitative evidence, it is concluded that surface diffusion is the transport process controlling sintering under the conditions of the present studies. The results of this investigation are at variance with those of previous studies. Possible reasons for the discrepancy are discussed.
\end{abstract}

\section{$R E ́ S U M E$}

La cinétique du frittage, dans l'air et en atmosphère réductrice, de sphères monocristallines de rutile a été étudiée dans le domaine de température compris entre 900 et $1350^{\circ} \mathrm{C}$. Le frittage est caractérisé par deux stades: un stade initial à vitesse faible, suivi par une période de frittage plus rapide. En même temps que le changement de la vitesse de frittage on observe lapparition de facettes planes à la surface des sphères de rutile. Les auteurs suggèrent que c'est ce phéno- mène qui est responsable de laugmentation de la vitesse de frittage.

En s'appuyant sur des preuves de nature qualitative aussi bien que quantitative, ils concluent que le mécanisme de transport qui détermine la cinétique du frittage dans les conditions de leur étude est la diffusion superficielle. Ces résultats ne sont pas en accord avec les conclusions d'études antérieures. Les auteurs examinent plusieurs facteurs pouvant expliquer ce désaccord.

\section{ZUSAMMENFASSUNG}

Das Sintern einkristalliner Rutilkugeln wurde in Luft und in reduzierender Atmosphäre im Temperaturbereich 900 bis $1350^{\circ} \mathrm{C}$ untersucht. Die Sintergeschwindigkeit ist durch zwei Stufen charakterisiert: zunächst eine niedrige Geschwindigkeit am Anfang und dann eine schnellere Periode. Gleichzeitig mit den Änderungen der Sintergeschwindigkeit bilden sich flache Oberflächen auf den Rutilkugeln. Es wird vermutet, daß diese Erscheinung die Änderung der Sintergeschwindigkeit hervorruft.

Aus qualitativen und quantitativen Ergebnissen wird gefolgert, daß unter den vorliegenden Bedingungen die Oberflächendiffusion der das Sintern bestimmende Transportprozeß ist. Die Ergebnisse dieser Untersuchung weichen von denen früherer Untersuchungen ab. Mögliche Gründe für die Diskrepanz werden diskutiert.

\footnotetext{
* Present address: Bell Telephone Laboratories, Inc., Murray Hill, N.J.
} 


\section{INTRODUCTION}

In recent years a number of studies have been devoted to the sintering behavior of rutile. The investigations were concerned with experiments on single crystals in which the growth of a neck between two spheres or between a sphere and a plate is observed, and on polycrystalline samples in which the change in linear dimensions of a powdered compact is followed. Sintering in the single crystal experiments was interpreted in terms of three different transport processes, plastic flow ${ }^{1}$, volume diffusion ${ }^{2}$ and evaporation condensation ${ }^{3}$. The early data on powder compacts were correlated with semi-empirical equations for a volume diffusion process ${ }^{4,5}$. A more recent and more complete study indicated that shrinkage in a powder compact follows grain boundary diffusion kinetics after a short initial period in which volume diffusion controls ${ }^{6}$.

In the two detailed experiments with single crystal rutile the experimental conditions were similar. Yet not only are the sintering data qualitatively different as to suggest different mechanisms but the quantitative aspect, i.e., the times to produce an equivalent neck size, differ by an order of magnitude. For instance, in one study ${ }^{1}$ it was found that $1 \mathrm{~mm}$ rutile spheres (Linde), fired in air, developed a neck of $0.15 \mathrm{~mm}$ diameter in 650 minutes at $1200^{\circ} \mathrm{C}$, while 15 minutes were required for the formation of a neck of similar size at $1150^{\circ} \mathrm{C}$ in reducing atmosphere composed of hydrogen and steam $\left(P_{\mathrm{O}_{2}}=\right.$ $\left.10^{-14}\right)$. On the other hand, in the second study ${ }^{2}$, it was found that $2 \times 10^{4}$ minutes were required to form a neck of $0.15 \mathrm{~mm}$ diameter on vacuum-reduced samples $\left(P_{\mathrm{O}_{2}}=10^{-7}\right)$ at $1200^{\circ} \mathrm{C}$ for similar spheres. The reason for this discordant behavior has not been explained.

The only significant difference between these studies is the method by which the reduced rutile was prepared or pretreated. Previously, it was suggested ${ }^{7}$ that the defect species present in nonstoichiometric rutile depended on the method of reduction. Recently the evidence available was reviewed ${ }^{8}$ and it was concluded that the interstitial cations form at total pressures $<10$ Torr and in low $\mathrm{O}_{2}$ atmosphere $\left(\mathrm{CO} / \mathrm{CO}_{2}\right.$ mixtures $)$ while anionic vacancies predominate in $\mathrm{H}_{2}$ at all pressures and at $\mathrm{O}_{2}$ pressures $>10$ Torr. Data were also presented to show that the rate of the anatase to rutile phase transformation depends very much on the defect species present.
The purpose of this communication is to reconcile the different data on the sintering behavior of rutile and to present new results on the initial period of sintering.

\section{EXPERIMENTAL SYSTEM}

The chemical composition of the single crystal rutile, the preparation of the microspheres, the equipment used for recording the increase in neck width as a function of time, and the procedure followed for obtaining and treating the experimental data have been discussed in detail previously ${ }^{1}$. The spheres of $1 \mathrm{~mm}$ diameter were obtained from a commercial source (Linde), while spheres of other diameters were prepared from boules of Verneuil grown rutile.

The spheres were mounted in a groove of a $\mathrm{Pt}$ resistance heater wire and set directly in the field of an optical microscope. A filar stage in the microscope eyepiece permitted measurement of changes in neck size as a function of time at sintering temperatures. A stream of air or mixtures of $\mathrm{H}_{2} \mathrm{O}+$ $\mathrm{H}_{2}$ was slowly passed through the hot stage during sintering measurements.

\section{RESULTS}

The rates of neck growth in air appear in Fig. 1 for $1100^{\circ} \mathrm{C}$ to $1350^{\circ} \mathrm{C}$, where $x / a$ represents the ratio of the neck diameter to sphere diameter. Figure 2 shows similar data in an atmosphere of $P_{\mathrm{H}_{2}} / P_{\mathrm{H}_{2} \mathrm{O}}=$ 10 for $900^{\circ}$ to $1150^{\circ} \mathrm{C}$. The rutile phase is a stable phase under these conditions. Indeed, $\mathrm{X}$-ray analysis disclosed only a tetragonal phase while the weight change between air-fired and reduced material was found smaller than that required to convert stoichiometric rutile to the titanium oxide phase with the next highest oxygen content.

The curves in Fig. 1 and Fig. 2 show that there are two rate periods. At $x / a \cong 0.8$ the reciprocal slope of the sintering curve changes from a value of 7 to the value of 2 . The latter value was reported earlier ${ }^{1}$. The time at which the change in slope occurs is seen to be dependent on temperature. Activation energies were calculated for each rate period and for both atmospheres by utilizing the times to produce a comparable increase in neck size during each sintering period. The value of all four energies is $68 \pm 5$ $\mathrm{kcal} / \mathrm{mole}$. Spheres with diameters other than $1 \mathrm{~mm}$ 

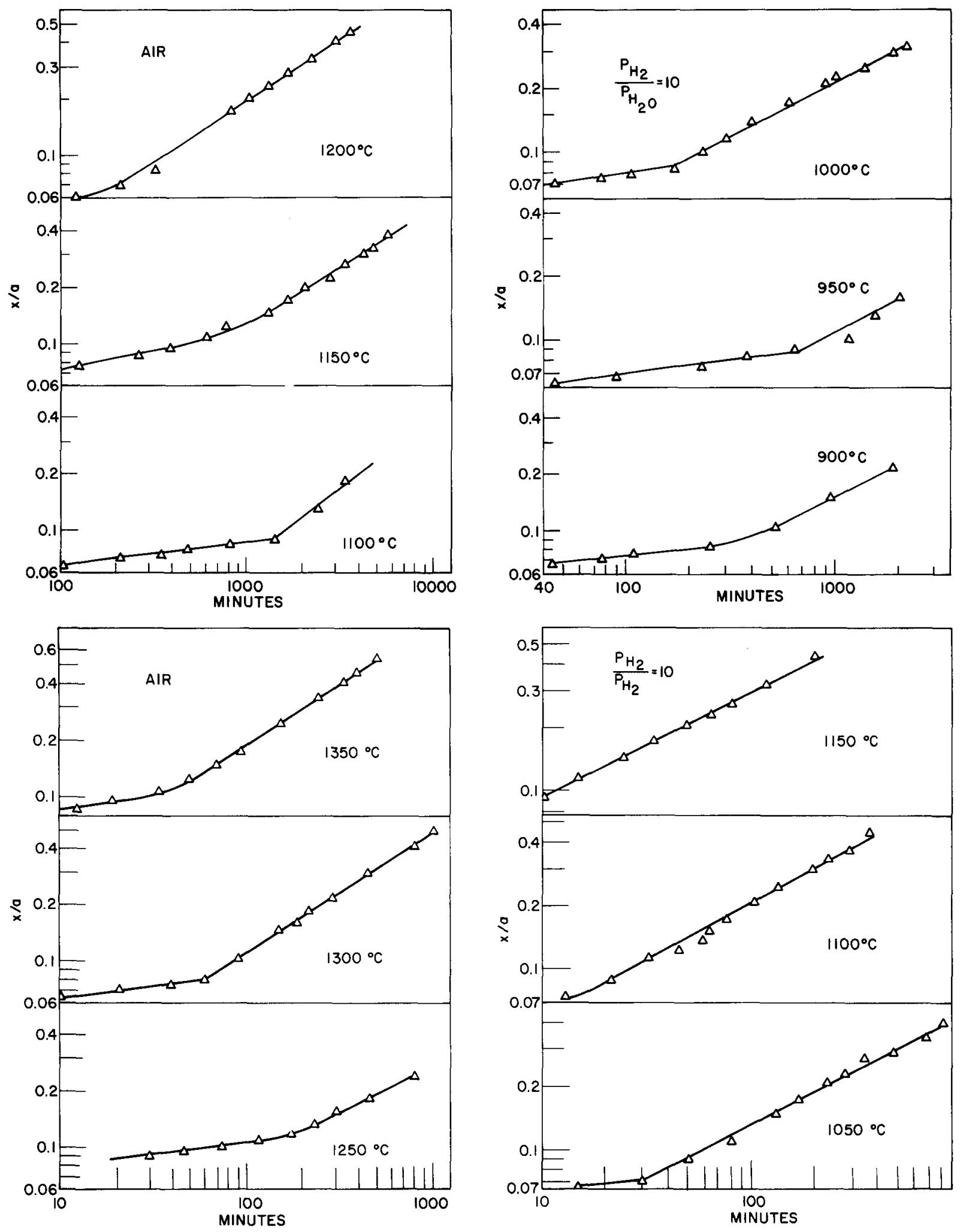

Fig. 1. Time and temperature dependence of the ratio of neck-toparticle radius, $x / a$, for $1 \mathrm{~mm}$ diameter $\mathrm{TiO}_{2}$ spheres sintered in

Fig. 2. Time and temperature dependence of the ratio of neck-toparticle radius, $x / a$, for $1 \mathrm{~mm}$ diameter $\mathrm{TiO}_{2}$ spheres sintered in reducing atmosphere $\left(\boldsymbol{P}_{\mathrm{H}_{2}} / P_{\mathrm{H}_{2} \mathrm{O}}=10\right)$. 


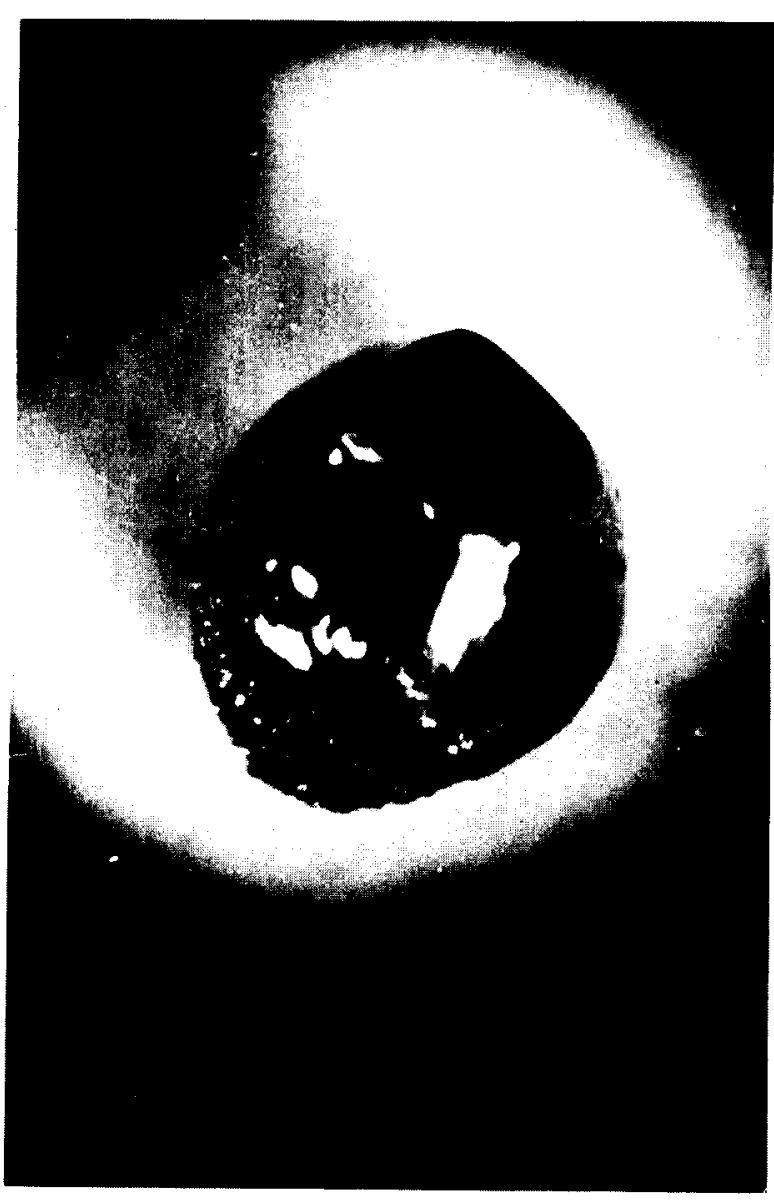

Fig. 3. Formation of facets on $\mathrm{TiO}_{2}$ single crystal spheres sintered in low oxygen atmosphere $\left(P_{\mathrm{O}_{2}}=0.02\right)$ at $1250^{\circ} \mathrm{C}$ for 800 minutes.

showed qualitatively the same sintering behavior. However, no firm quantitative relationship between size and sintering rate could be established because the spheres with diameters other than $1.0 \mathrm{~mm}$ lacked good surface finish and sphericity. No change in center-to-center distance between unsintered and sintered pairs of spheres was detected.

During the course of the sintering, facets formed on the sphere surfaces. The morphology of these facets depended on the atmosphere. The facets formed in a low oxygen atmosphere (Fig. 3) had a very smooth appearance. Those developed in the $\mathrm{H}_{2}+\mathrm{H}_{2} \mathrm{O}$ atmosphere were at first (Fig. 4) composed of a band of minute striations around the diameter. Subsequently these striations became smoothed and the facets covered the entire sphere (Fig. 5). The time for the appearance of the facets was strongly dependent on the temperature and atmosphere. Spheres extensively covered with facets showed no observable loss of weight $(<0.25 \%)$.

\section{DISCUSSION}

For systems with spherical geometry a useful rate expression to describe the neck growth between spheres is of the type ${ }^{9}:(x / a)^{n}=K t$, where $K$ is a constant characteristic of the mechanism of sintering and $t$ is the time. The value of the exponent, $n$, is dependent upon the transport process causing sintering. For rutile sintered in air and in wet $\mathrm{H}_{2}$ the initial period $(x / a)<0.08$ showed a rate exponent $n=7$ which indicates surface diffusion as the predominant transport process responsible for sintering. At $(x / a) \approx 0.08$ the rate exponent changed to $n=2$. We suggest that this change in exponent is connected with the development of flat surfaces in the region of the neck. Previously, a change in exponent during the sintering of $\mathrm{Al}_{2} \mathrm{O}_{3}$ spheres in dry $\mathrm{H}_{2}$ was reported ${ }^{10}$, and the change in exponent from $n=5$ (volume diffusion) to $n=3$ coincided with the appearance of facets on the spheres. Although

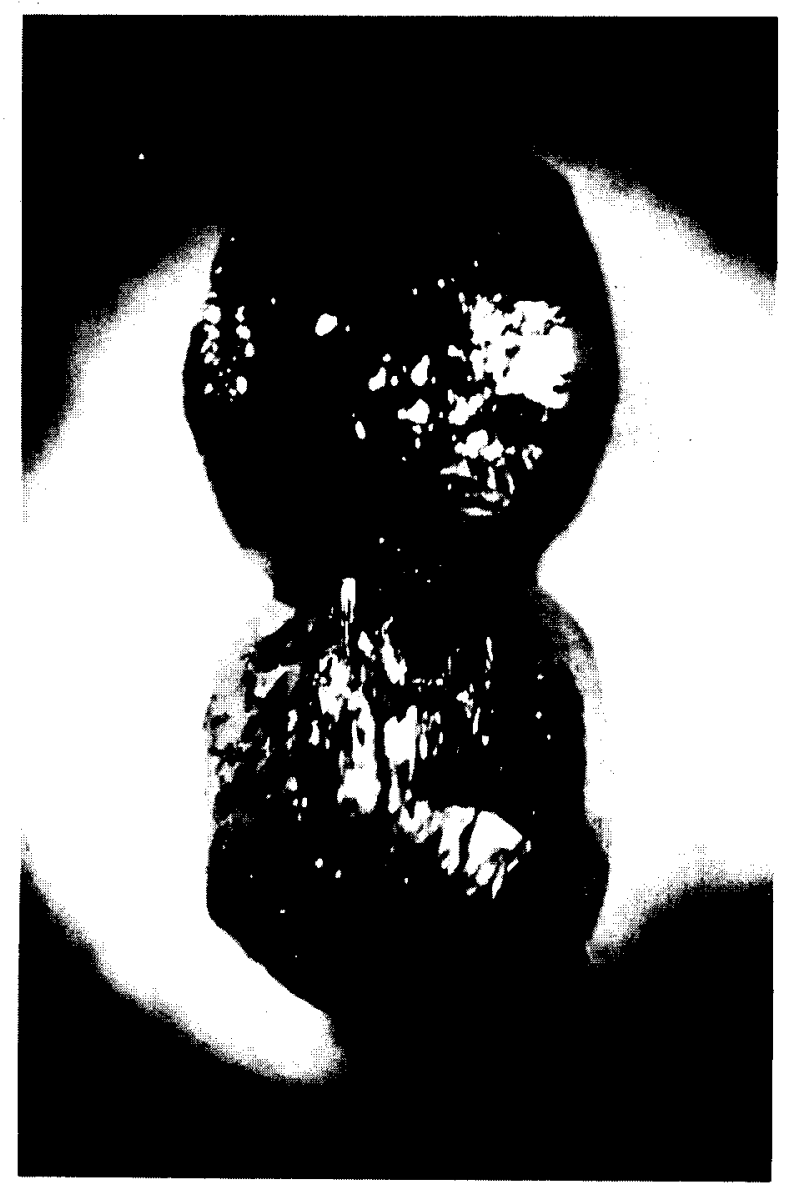

Fig. 4. $\mathrm{TiO}_{2}$ single crystal spheres sintered in reducing atmosphere $\left(P_{\mathrm{H}_{2}} / P_{\mathrm{H}_{2} \mathrm{O}}=10\right)$ at $1050^{\circ} \mathrm{C}$ for 800 minutes. 


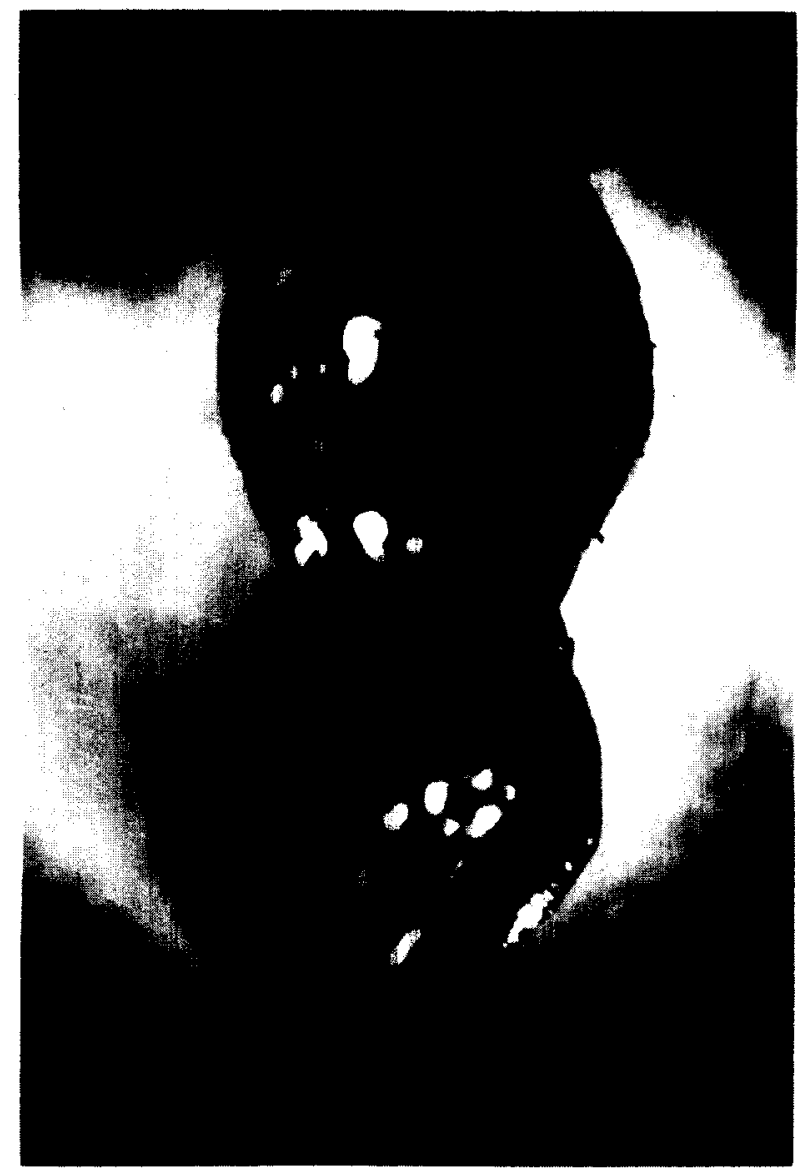

Fig. 5. $\mathrm{TiO}_{2}$ single crystal spheres sintered in reducing atmosphere $\left(P_{\mathrm{H}_{2}} / P_{\mathrm{H}_{2} \mathrm{O}}=10\right)$ at $1200^{\circ} \mathrm{C}$ for 600 minutes

it was judgea that these facets were formed by evaporation, volume diffusion was considered to be the transport process responsible for sintering during both rate periods. In the present research, although no facets could be detected at the time at which the sintering rate changed, the times for the development of the facets and that for the rate change were similarly dependent on temperature and atmosphere. In addition, the activation energy for both rate periods was similar, $68 \mathrm{kcal} /$ mole. These facts are taken as suggesting that surface diffusion was the preponderant transport mecha- nism for sintering throughout the present experiments. If this conclusion is accepted the value of $n=2$ should not be taken as an indication that plastic flow is the preponderant transport process, as the formal theory would require ${ }^{8}$ and as it was previously proposed ${ }^{1}$.

Some information concerning this diffusion process observed in this study can be obtained from the dependence of sintering kinetics on atmosphere and temperature. If the migration of oxygen ions via vacancies is rate-controlling then the time to achieve a similar neck geometry should be shorter in the reducing atmosphere since this atmosphere produces a larger number of anion vacancies. Table 1 shows that at the temperatures where a comparison is possible the sintering times in the reducing atmosphere are about 40 times faster.

For equilibrium between the gas and solid the relative number of unassociated anion vacancies in pure rutile $\left(\sim P_{\mathrm{O}_{2}}^{-\frac{1}{6}}\right)$ is calculated to be 250 to 350 times greater for the reducing atmosphere. Any degree of association between vacancies would cause a large dependence. The major factor for this disagreement between the experimental and theoretical sintering rate increases is the presence of a small amount of aluminum in Linde rutile. This aluminum produces anion vacancies the number of which is not related to oxygen pressure.

There are no data on surface diffusion coefficients of oxygen on rutile. Indeed, surface diffusion processes are generally poorly understood for all materials. It is known that oxygen volume diffusion in rutile has an activation energy of $60 \mathrm{kcal} / \mathrm{mole}^{11}$, a value not too different from the $68 \pm 5 \mathrm{kcal} / \mathrm{mole}$ of this study. The similarity may be coincidental, but an analogous relation of activation energies exists for copper diffusion. Surface self-diffusion of copper has been reported with activation energies of $55 \mathrm{kcal} / \mathrm{mole}$ (from sintering) and $49 \mathrm{kcal} / \mathrm{mole}$ (from thermal grooving) while volume self-diffusion has an activation energy of $46 \mathrm{kcal} / \mathrm{mole}^{12}$.

In the initial sintering period the experimental results can be fitted by a sintering rate expression

TABLE 1: OXYGEN PRESSURE DEPENDENCE OF SINTERING TIME

\begin{tabular}{lllcc}
\hline & Atm. & $P_{O_{2}}$ & Time $\left(\frac{x}{a}=0.08\right)$ & Time $\left(\frac{x}{a}=0.2\right)$ \\
\hline $1100^{\circ} \mathrm{C}$ & Air & $10^{-0.7}$ & $200 \mathrm{~min}$ & 2100 \\
& $P_{\mathrm{H}_{2}} / P_{\mathrm{H}_{2} \mathrm{O}}=10$ & $10^{-15.2}$ & $<10$ & 45 \\
$1150^{\circ} \mathrm{C}$ & Air & $10^{-0.7}$ & 600 & 4000 \\
& $P_{\mathrm{H}_{2}} / P_{\mathrm{H}_{2} \mathrm{O}}=10$ & $10^{-14.6}$ & 20 & 100 \\
\hline
\end{tabular}


derived for surface diffusion ${ }^{9}$ :

$$
\left(\frac{x}{a}\right)^{7}=\frac{2 D_{s} \Omega^{2} n s}{a^{4} K T} t
$$

Taking $a=0.05 \mathrm{~cm}, \gamma$ (surface tension) $=10^{3} \mathrm{ergs} /$ $\mathrm{cm}^{2}, \Omega$ (atomic volume) $=10^{-23} \mathrm{~cm}^{2} /$ atom, $n_{s}$ (surface atom concentration) $=10^{14}$ atom $/ \mathrm{cm}^{2}$, and using the experimental results for $x / a=0.08$ at $t=600 \mathrm{sec}$ and $T=1100^{\circ} \mathrm{C}$, a value for the surface diffusion coefficient $D_{s}=1.2 \mathrm{~cm}^{2} / \mathrm{sec}$ can be calculated for sintering in reducing atmosphere. For a similar amount of sintering in air at the same temperature, $D_{\mathrm{s}}=3.0 \times 10^{-2} \mathrm{~cm}^{2} / \mathrm{sec}$.

It should also be remarked that mass transport by an evaporation condensation mechanism is unlikely. The results do not yield the appropriate rate exponent. The vaporization energy of rutile ${ }^{13}$ is about $70 \mathrm{kcal} / \mathrm{mole}$ larger than the observed activation energy, and the vapor pressure at $1800^{\circ} \mathrm{K}$, calculated from the free energy functions for gaseous $^{13}$ and solid rutile ${ }^{14}$, is six orders of magnitude lower than that required to give the sintering rates observed at $1350^{\circ} \mathrm{C}$.

In previous experiments on an apparently similar system and employing similar techniques, a sintering rate much slower than that observed in the present investigation was reported ${ }^{2}$. The experimental evidence favored a transport process based on volume diffusion. If, as discussed earlier, these experiments were performed on a material which contained interstitial titanium ions, one would expect that the number of anion vacancies available for diffusion would be strongly decreased. The presence of interstitials might also be expected to alter the crystal surface and possibly prevent surface migration. If the rate-limiting step in the volume diffusion process were the migration of oxygen ions as suggested, the presence of titanium on interstitial lattice sites would be expected to make the transfer of oxygen more difficult. This is consistent with the known fact that the activation energy for sintering controlled by volume diffusion of oxygen $(74 \mathrm{kcal} /$ mole $)^{2}$ is larger than that for the volume selfdiffusion of oxygen $(60 \mathrm{kcal} / \mathrm{mole})^{12}$.

\section{CONCLUSIONS}

The sintering of single crystal rutile spheres is a diffusion-controlled process. The nature of the defect structure determines whether surface diffusion or volume diffusion is the preponderant transport process. In air or wet $\mathbf{H}_{2}$ atmospheres, where the predominant defects are anion vacancies, sintering proceeds by surface diffusion. The appearance of facets is found to have a pronounced effect on the sintering rate.

\section{ACKNOWLEDGEMENT}

This research was supported by the Air Force Office Scientific Research under contract No. AF 49(638)493. This support is gratefully acknowledged.

\section{REFERENCES}

1 H. M. O'Bryan, JR. and G. Parrayano, in W. Leszynski (ed.), Powder Metallurgy, Wiley/Interscience, New York, 1961 , p. 191.

2 D. H. Whitmore and T. Kawai, J. Am. Ceram. Soc., 45 (8) (1962) 375.

3 A. G. Grotyhann and K. Herrington, J. Am. Ceram. Soc., 47 (1) (1964) 53.

4 D. Hiltmann and G. Spiess, Tonind.-Ztg. u. Keram. Rundschau, 82 (1958) 38.

5 A. C. D. Chaklader and J. Thiriar, Compt. Rend., 259 (21 Sept. 1964) 1969.

6 H. V. Anderson, Am. Ceram. Soc. Ann. Meeting, Washington, D.C., May 8, 1966, paper 7-B-66.

7 P. F. Chester, J. Appl. Phys., $32 S$ (1961) 2233.

8 R. D. Shannon, J. Appl. Phys., 35 (11) (1964) 3914.

9 G. C. KuCZYNSKI, Trans. AIME, 185 (2) (1949) 169.

10 G. C. Kuczynski, L. Abernathy and J. Allan, in W. D. KIngery, Kinetics of High Temperature Processes, John Wiley, 1959, p. 163.

11 R. Haul And G. Dumbgen, J. Phys. Chem. Solids, 26 (1) (1965) 1.

12 J. M. Blakely, Progr. Mater. Sci., 10 (4) (1963) 395.

13 R. J. ACKermann and R. J. Thorn, Progr. Ceram. Sci., 1 (1961) 39.

14 G. N. Lewis and M. Randall, Thermodynamics, revised edition, McGraw-Hill, 1961, p. 677. 